\title{
Editorial
}

European

Thyroid Journal
Eur Thyroid J 2019;8:171-172

DOI: $10.1159 / 000501853$

Published online: July 5, 2019

\section{New Impact for the Journal}

The European Thyroid Journal (ETJ) is now in its 8th year of existence and has earned its own place in the biomedical literature. When we started the journal back in 2011, I considered it as an experiment and experiments can either succeed or fail. Failure seems no longer possible: the journal is here to stay. The number of submitted papers gradually increased over the years, and its flow was more than sufficient to support the transition from a quarterly journal to a bimonthly journal 2 years ago without jeopardizing the quality. Quality is key to the journal, and reviewers are instrumental to safeguard the scientific quality of our published papers. As a courtesy to our reviewers, we list below the names of all who have reviewed for the journal in 2018. The journal has gone much further in acknowledging the essential role of reviewers by establishing the ETJ Best Reviewer Award. Criteria are the number of reviews done for the journal, the quality of the reviews, and the speed in which the reviews are returned. Winners have been Maria Alevizaki in 2016, Steen Bonnema in 2017, George J. Kahaly in 2018, and Kris Poppe in 2019. Awards are presented at the opening session of the annual ETA meeting and consist of a plaque and reimbursement of the registration fee and travel expenses to the annual meeting. ETJ is the formal journal of the European Thyroid Association (ETA), and as such the natural home of ETA guidelines. Up to now, we have published 16 guidelines, on average 2 per year. We publish on all aspects of thyroidology, but consistent with patients' and clinicians' current needs, thyroid cancer, Graves' orbitopathy, and T4 + T3 combination therapy are topics of special attention. Whereas about $50 \%$ of submissions have come from Europe, 25\% are derived from Asia, 20\% from North America and Latin America, and 5\% from elsewhere. The journal thus has developed a truly international flavor.

It took a relatively long time before ETJ was given an impact factor. Impact factors of biomedical journals are calculated based on citation rates and curated by a commercial company called Clarivate. The process by which a journal is given an impact factor lacks transparency and there is no right of appeal. Although there is much doubt about the value attached to impact factors, many universities worldwide still use the impact factors as a tool to evaluate the scientific standing of their professors, departments etc. It seems incongruous that such a relevant evaluation tool for academia is completely at the whim of a commercial company. The more so because one is at a loss when e.g. administrative errors result in no impact factor. Against this background I am delighted to announce that ETJ just got its first impact factor of 3.025. This lies around the median rank for journals in endocrinology and metabolism, and is significantly better than several longer established publications. This is the new impact for the Journal and is an excellent first entry, reflecting the number of ETJ papers cited over 2017 and 2018. We hope this innovation will stimulate more submissions, especially in the field of basic thyroidology. The other new impact for the Journal is that we will have a new editor-in-chief as of July 1st, 2019: Simon Pearce. Simon is a long-standing supporter of the Journal, having submitted a paper on the first day that the manuscript submission system "went live," in October 2011. In his capacity as associate editor for Clinical Thyroidology he knows the Journal very well already, thereby securing a seamless transition. Patrice Rodien from Angers will succeed Simon as associate editor for Clinical Thyroidology.

\section{KARGER}

E-Mail karger@karger.com

www.karger.com/etj
(C) 2019 European Thyroid Association

Published by S. Karger AG, Basel 
Personal Comment from Simon. As the incoming Editor-in-Chief, I need to pay a personal tribute to Wilmar Wiersinga for his vision in 2011 of developing and launching ETJ as the official journal of the European Thyroid Association, and for his tireless hard work over the last 9 years to guide it through to its current position. This has been a great service for the global community involved in the science and clinical art of thyroidology as well as for the European Thyroid Association. With the newly des- ignated impact factor, Wilmar leaves the Journal in excellent standing for the future. As well as my sincere personal thanks for trusting me with this legacy, the President, Officers and Members of ETA also acknowledge a debt to Wilmar's talents and dedication in steering ETJ to its current strong position.

Wilmar M. Wiersinga, Amsterdam Simon H. Pearce, Newcastle-upon-Tyne

\section{Acknowledgements to Reviewers 2018}

Maria Alevizaki, Athens

Martin Almquist, Lund

Ali Alzahrani, Riyadh

Bjorn Asvold, Trondheim

Saba Balasubramanian, Sheffield

Agnieszka Baranowska-Bik, Warsaw

Luigi Bartalena, Varese

Paolo Beck-Peccoz, Milan

Tomasz Bednarczuk, Warsaw

Finn Noe Bennedbaek, Herlev

Arie Berghout, Rotterdam

Jérome Bertherat, Paris

Nikola Besic, Ljubljana

Martin Biermann, Bergen

Bernadette Biondi, Naples

Kristien Boelaert, Birmingham

Anita Boelen, Amsterdam

Steen Bonnema, Odense

Georg Brabant, Lübeck

Lucia Brilli, Siena

Philippe Caron, Toulouse

Maria Grazia Castagna, Siena

Filomena Cetani, Pisa

Layal Chaker, Rotterdam

Iacopo Chiodini, Milan

Luca Chiavato, Pavia

Carla Colombo, Milan

Bernard Corvilain, Bruxelles

Giuseppe Costante, Bruxelles

Chantal Daumerie, Bruxelles

Amirezza Dehghanian, Shiraz

Joanne Donkers, Amsterdam

Henning Dralle, Essen

Robin Dullaart, Groningen

Leonidas Duntas, Athens

Grigoris Effraimidis, Copenhagen
Rossella Elisei, Pisa

Murat Erdogan, Ankara

Sam Evans, Swansea

Csaba Fekete, Budapest

Laura Fugazzola, Milan

Earn Gan, Newcastle-upon-Tyne

Ober Gomez Lopez, Vienna

Paul Graham, Houston, TX

Laszlo Hegedus, Odense

Martin Hewison, Birmingham

Stephen Hyer, Carshalton

Rajko Jovic, Novi Sad

George J. Kahaly, Mainz

Eva Kassi, Athens

Jukka Kero, Turku

John Lazarus, Cardiff

Thera Links, Groningen

Heather Lochnan, Ottawa, ON

Rui Maciel, Sao Paolo

Mohamad Maghnie, Genova

Maria Chiara Maiuri, Bruxelles

Marie-Christine Many, Bruxelles

Claudio Marcocci, Pisa

Elizabeth McAninch, Chicago, IL

Caterina Mian, Padova

Ahmad Monabati, Shiraz

Fabio Monzani, Pisa

Carla Moran, Cambridge

Syed Morshed, New York, NY

Fadi Murad, Baltimore, MD

Roberto Negro, Lecce

Marek Niedziela, Poznan

Els Nieveen-van Dijkum, Amsterdam

Vijay Panicker, Nedlands, WA

Ralf Paschke, Calgary, $\mathrm{AB}$
Kalliopi Pazaltou-Panayiotou,

Thessaloniki

Simon Pearce, Newcastle-upon-Tyne

Luca Persani, Milan

Luciano Pezzullo, Naples

Patrick Pilkington Woll, Madrid

David Poller, Portsmouth

Kris Poppe, Bruxelles

Ruth Prichard, Dublin

Efisio Puxeddu, Perugia

Harpal Randeva, Warwick

Gregory Randolph, Boston, MD

Ase Krogh Rasmussen, Copenhagen

Patrice Rodien, Angers

Mario Rotondi, Pavia

Mario Salvi, Milan

Paola Vincenza Sartori, Desio

Ashok Shaha, New York, NY

Yehuda Shoenfeld, Tel-Hashomer

Eleanor Simonsick, Baltimore, MD

Alex Stagnaro-Green, Rockford, IL

Mihaela Stefan, New York, NY

Peter Taylor, Cardiff

Francesco Trimarchi, Messina

Jeremy Turner, Norwich

Bijay Vaidya, Exeter

Suresh Vaikkakara, Tirupati

Frederik Verburg, Marburg

Edward Visser, Rotterdam

Paolo Vitti, Pisa

Natsuko Watanabe, Tokyo

Torquil Watt, Copenhagen

Wilmar Wiersinga, Amsterdam

Afshan Zahedi, Toronto, ON

Denise Zwanziger, Essen 